\title{
Р.М. Хамитов
}

\section{ИНТЕРПРЕТАЦИЯ КАК СРЕДСТВО ПОГРУЖЕНИЯ В ИСТОРИЧЕСКУЮ ДЕЙСТВИТЕЛЬНОСТЬ В КОНТЕКСТЕ ГУМАНИТАРНОГО ПРОЕКТА В. ДИЛЬТЕЯ}

\begin{abstract}
Искусство понимания, или герменевтика, имеет богатую историю, которая берет начало в Античности у Аристотеля, по большей части выступает средством расшифровки грамматических структур, далее сквозь Средневековье от толкования Библии к толкованию литературы мирского характера она приобретает характер универсальности, а в случае дильтеевской герменевтики становится фундаментом наук о духе.

Ключевые слова: Дильтей, интерпретация, история, герменевтика.
\end{abstract}

Исследуется проблема соотношения философии и исторической науки в учении В. Дильтея. Метафизические построения с XIX в. подвергались критике и нивелированию. До конца же избежать их, как оказалось, не удавалось и не удаётся, если в проблемном поле лежит стремление обосновать самостоятельность такого рода сферы, как науки о духе, в которых помещается интерес ко всему, что имеет отношение к человеческой культуре. При поиске ответа на обозначенный вопрос возникают дополнительные трудности, которые в дальнейшем создают новые проблемы.

Время Дильтея, ознаменованное сомнениями человека в собственной значимости, а также в значимости истины, возможно, из-за критических настроений стало победоносным для историзма. После переосмысления истории романтиками Дильтей пытался согласовать подготовленную ими базу с эмпирическими данными исторической науки. При этом возникает вопрос, учитывая всеобщность исторического процесса, каким образом можно быть объективно ответственным за него. В мире человеческих творений нет ничего законченного, и все в истории со временем обретает новые качества, новые способы и результаты осмысления.

И исследователь, и действующий человек, как правило, выступают релятивистами, они привычно склоняются к историческому прояснению окончательности и однозначности любого события. В этом случае предаётся забвению то, что индивидуальность не изолирована и не существует в лабораторных условиях, что историческое, во всем своем объеме, должно подлежать рассмотрению в перспективе развития, жизненной взаимосвязи между собой моментов устойчивости и изменчивости, за исключением, повидимому, лишь самосознания, в котором личность находится в самотождественности и одиночестве.

Исследователь, по Дильтею, рассматривая включённость исторического события во взаимодействия, призван учитывать порождаемую в них ценность бытия и актуальность цели. Связь продуктов исторической действительности создается самой исторической жизнью, которая в своей сущности основана и 
передаёт душевные переживания деятелей. Результатами истории здесь являются как подчиняющие индивидов цели и правила, так и исторические понятия, к которым относится помимо действий, событий и т.П., само течение времени духовной действительности.

Наибольшее влияние на Дильтея в этом отношении оказал Гегель, именно благодаря его диалектическому методу Дильтей смог охватить изобилие красок исторической жизни. Метод Гегеля был подвергнут Дильтеем корректировке. Понимание, которое Гегель основывал на идеальных конструкциях, Дильтей заменил концептом жизни как тотальной взаимосвязи душевных элементов. Таким образом, метафизическое конструирование упразднялось и было заменено анализом данных в историческом выражении жизненной связи. «Историк-прагматик и Гегель не слышат друг друга, ибо первый крепко стоит на земле, а второй вещает с заоблачных высей. И тем не менее каждый из них отчасти прав. Ведь скрытой пружиной всего, что в исторически общественной действительности приводится в движение деятельностью человека, является его воля, а мотивом ее действий - целесообразность» [1. С. 329-330]. Из указанного выше становится ясным, как воля и целесообразность способствуют тому, что понимание исторических переплетений, энергии жизненной связи и её осмысления, сохранялось посредством обмена результатами и фиксацией этого обмена, полученными индивидами в процессе жизненного взаимодействия. Начало этой взаимосвязи у Дильтея выражалось переживанием и пониманием, которые становились возможными благодаря тому, что индивид видел в исторических результатах свое собственное выражение.

Рассматривая вопрос о коррективах Дильтея, необходимо иметь в виду, что преобразование узлового понятия учения Гегеля затевалось не во имя преодоления гегелевской метафизики. Дильтею важно показать особенности и суть исторического сознания, которое выступало у него в качестве самоочевидности духа, в нём происходит не только появление, но и возвращение объективаций жизни в изначальное состояние переживаний.

Дильтеевская вера в историчность сознания безгранична, он настаивал на указании онтологической сути переживания прошлого. Отстраняясь от гегелевской метафизики, он продолжал опираться на идеал абсолютного духа, в котором происходило перемещение из начальной ступени переживания в мир вечного разума. Реализация человеческого духа в структуре жизненной связи осуществляется бесконечно. У Дильтея историческое сознание вставало на место метафизического сознания. Вместе с тем этот проект явился радикальным и в отношении его собственной метафизичности: бесконечность духа, сохраняя свою тайну, существует как скрытый союз с непознаваемым космосом.

Дильтей представлял это следующим образом. Предмет обретает свое происхождение в истории, но сохраняет по отношению к безграничному пониманию свою независимость, касающуюся исследования любого факта в рассматриваемом историческом контексте. При этом идентичность сознания с предметом не устанавливается в одночасье. Опытная историческая наука вытекает путем такого проектирования, которое осуществляется за кулисами всяческой спекуляции, что служит цели - замедлить встречу духа 
с самим собой, и в той же степени определить его завершение. Позднее у Гадамера вырисовывался близкий ход мысли: «В эпоху, когда в общественную практику все больше и больше проникает наука, она может осуществлять свою общественную функцию соответствующим образом лишь тогда, когда не скрывает своих границ и условности своего поля деятельности» [2. С. 315]. Здесь, хотя и критикуется идеалистическая рефлексия философии, но при этом сохраняется картезианское сознание, в котором, помимо прочего, присутствует имманентная бесконечность субъекта.

Проблема релятивизма полностью не исчезает при привлечении Дильтеем к исследованию таких категорий, как ценность, значение, цель. Так, утверждение Дильтея, что «взаимосвязь течения жизни может быть постигнута лишь посредством категории “значения”» [3. С. 281], логически вытекает из того факта, что история относится к наукам о человеке. Кроме этой категории, может привлекаться множество других категорий. И все же история соответствует процессу образования, рассматривает, как производится жизнь, ею не осуществляется принятие решения вести ненормированную борьбу между разными системами счислений. Отказ от умозрительного вмешательства исследователями в область истории, по Дильтею, должен осуществляться принципиально, так как философия не смогла решить вопрос релятивизма. Активность структурных отношений может господствовать в любое время и определять жизнь человека, что связано с единственно очевидным смыслом истории. Анализируя устройство духовного мира, мы получаем возможность рассмотреть определенную регулярность в предыдущем развитии, чтобы произвести установку существующего внутреннего порядка событий и прогнозировать будущее. В исторической случайности, которая, несмотря на то, что возможность прогнозирования не так редка, пока еще не многое понятно. Но интерпретация охватывает множество сторон наблюдаемого, и с увеличением различных способов и модификаций интерпретирования шансы достичь истинного понимания хода истории неуклонно повышаются.

Постоянный интерес Дильтея к исторической науке имел две отрицательные в своем определении стороны. Во-первых, история низводилась до коренящейся во всех гуманитарных науках дисциплине, не выходящей на поверхность в качестве действительной научной области, заслуживающей самостоятельности. Во-вторых, опровергалось существование философии истории, аргументом здесь выступало убеждение Дильтея в том, что история не имеет и не может иметь цели, будущее, в целом, непредсказуемо. Вместе с тем он умело пользовался разработанными Гегелем в рамках философии истории инструментами для построения собственного проекта гуманитарного знания, заменив концепт мышления понятием жизни. Воспринимая историческую действительность, сотворенную человечеством, как текст, Дильтей в основу своего проекта поставил дисциплину, целью которой является глубинное понимание культурных продуктов человечества.

Герменевтика позволяет проникать в индивидуальное как в предмет исследования наук о духе, индивидуальное - это не только внутренний мир личности, но и целая историческая эпоха. Единичное становится понятным при его введении в область всеобеего. Ограничением применения интро спекции служит жизненный опыт исследователя. Наблюдение над собой не 
дает гарантий в том, что его можно экстраполировать на внутренний мир другого человека. «Интроспекция открывает нам лишь малую часть человеческой жизни, которая доступна индивидуальному опыту: она не в состоянии охватить весь спектр человеческих феноменов» [4. С. 444]. Появляется задача избавиться от этой ограниченности в исследовании духовного мира.

Избавление от этого и других ограничений осуществляется Дильтеем при помощи интерпретации. Интерпретация в толковании духовного мира зависит не только от своего предмета, но также и от самого толкователя, в этом месте обнаруживается сходство интерпретации с искусством. При этом предметом интерпретации выступают текстовые памятники.

Создание науки об истолковании текстовых источников - герменевтики было целью творчества Дильтея при создании основополагающего учения для всей области наук о духе. Герменевтика могла бы выполнять для гуманитарного знания ту же роль, что и логика - для мышления. Таким образом, недостатки интроспекции должна была преодолеть герменевтика, способная найти человеческий дух в истории, что могло быть обеспечено соединением истории и философии. При этом оставалось непонятным, каким образом осуществляется познание в науках о духе. Человеческий мир и его история познаются с помощью понимания, которое доступно человеку лишь потому, что он является человеком, живет в человеческом обществе, Гадамер как бы вторит Дильтею: «Исторический мир, которым занимается здесь познание, всегда является миром, уже образованным и сформированным человеческим духом» [2. С. 250]. Обращение к истории объяснятся вышеуказанным мнением, что только в сопоставлении себя с другим «Я» возможно постижение действительности духа.

Явным в данном положении является обращение к герменевтическому кругу, в котором индивидуальное является частью всеобщего, отметим специфичность этой связи в гуманитарных науках - все, что содержится в универсуме, есть и в его отдельно взятой частности.

Здесь обнаруживается противоречие в учении Дильтея. В стремлении достичь наиболее полноценного понимания, свободного от всех преград, он как бы забыл о главном принципе жизни - ее историчности. Человеческая жизнь конечна в отличие от бытия мира, но «для Дильтея сознание конечности не означало признания неизменной предельности и ограниченности сознания» [2. С. 260]. Преодоление противоречивости, скорее кажущейся, происходит с помощью исторического познания, имея связь с человечеством в истории, мы можем сопереживать происходящее вместе с историческими героями.

Психологизм был шатким основанием методологии гуманитарного знания, и Дильтей находит ему альтернативу в виде коммуникативной общности человеческих индивидов. Но долгое время данное решение было вне сферы внимания научного сообщества ввиду принципов, разработанных Дильтеем в ранний период творчества. Субъект-объектное ориентирование в исследовании материалов духовного мира в дильтеевской концепции все еще воспринималось другими учеными сквозь призму психологизма. На самом деле психологизм не давал возможности, по Дильтею, изучать жизнь, определенную им как тотальность, субъект и объект здесь рассматривались как два 
трансцендентных друг другу индивида. Дильтею в решении указанного вопроса нужно было «перестать рассматривать внутренний мир человека как реальность, изолированную от других реальностей этого рода» [5. С. 142]. Преодоление психологизма Дильтеем могло идти и шло в направлении от исследования индивидов к надындивидуальным структурам - жизненным взаимосвязям, не поддающимся переживанию, таким, как народ, этнос, нация и др. «Историческая взаимосвязь в результате должна быть понята как смысловая взаимосвязь, которая существенно превышает горизонт переживаний отдельного человека. Исторический мир является большим, более чуждым текстом, расшифровать который должна помочь герменевтика» [2. С. 538-539].

Попытка преодоления психологизма у Дильтея осуществлялась в рассмотрении триединой структуры переживание-выражение-понимание. Реконструкции подвергся первый ее элемент. Переживание не может быть фундаментом, на котором через его выражение происходил бы процесс понимания. Приоритет коммуникации у Дильтея имеет отношение к объективному духу, вмещающему в себя все культурное наследие человечества. Человеческая коммуникация сама производит исторически обусловленные системы объективного духа. Объективный дух имеет влияние на каждого индивида, находящегося в той или иной культурной системе. Объективный дух не рассматривался как поступательное развитие человеческого общества, этот факт отбрасывался на задний план. «В истории, таким образом, всегда присутствуют значимые смысловые ансамбли, которые, однако, нельзя, представить как прогрессивно сменяющие друг друга» [6. С. 42]. Теперь ясно, что дал отказ от психологизма Дильтею в постижении человеческой действительности, несмотря на то, что в действии каждого индивида не отрицается присущая ему целесообразность и целеполагание, все же он действует в рамках того исторического периода, где разворачиваются его действия, и в исследовании истории необходимо обращаться к соответствующим источникам, имеющим отношение к человеческой культуре.

За удалением из гуманитарного знания фактора интроспекции у Дильтея возникает, как объект понимания человеческого мира и его истории, выражающееся вовне переживание в качестве культурных влияний, которые, в свою очередь, для каждой личности выступают как нечто объективное и которые представляют медиальную структуру в общении индивидов. История сама в себе содержит основы для понимания, ведь именно в ней и живет индивид. Своими мыслями, изречениями их, действиями индивид создает почву для понимания. Все человеческие творения являются объективациями укорененных в человеке идей, образующих впоследствии историческую связь, доступную любому индивиду, переходя из внутреннего во внешнее проявление. И происходит это потому, что между членами общества существует коммуникативная общность. Существование категории общности базируется на тех структурах, что мы находим в культурных продуктах человечества. Они становятся понятными для нас, благодаря постижению их смысла - общему для каждого члена общества, таким образом, смысл является условием для интерсубъективности в структуре человеческого сообщества. 
Как верно отметил Г.Г. Шпет в своей феноменальной «Истории как проблеме логики» (см.: [7. С. 896-899]), гуманитарные науки по отношению к психологии стоят в позиции координации, но никак не подчинены и тем более не основаны на ней. Дело в том, что психология, даже описательная, теоретическая дисциплина и нуждается в обосновании. История же, пользующаяся психологией лишь в качестве средства разрешения некоторых проблем, не может быть объективной, полагаясь на психологию, в которой все силы брошены на постижение каждого индивида, пусть и имеющего коммуникативную общность с другими людьми. История как наука еще не сформировалась, реализация этого проекта осталась за рамками творчества Дильтея.

Но все же история, по Дильтею, имеет преимущества перед психологией в том плане, что, исследуя факты действительности в хронологическом порядке, она необходимо приходит к логическим выводам, и немаловажную роль в конечных результатах играет коммуникативная общность индивидов, стремление которых направлено на получение наиболее верифицированных продуктов исторической науки. Для определения научного статуса истории необходимо обратиться к современным герменевтическим концепциям в их рассмотрении методов исторической науки, но это дело отдельного исследования.

\section{Литература}

1. Дильтей В. Введение в науки о духе // В. Дильтей. Собрание сочинений: в 6 т. М.: Дом интеллектуальной книги, 2000. Т. 1.768 с.

2. Гадамер Г.Г. Истина и метод. М.: Прогресс, 1988. 704 с.

3. Дильтей В. Построение исторического мира в науках о духе // В. Дильтей. Собрание сочинений: в 6 т. М.: Три квадрата, 2004. Т. 3. 419 с.

4. Кассирер Э. Избранное. Опыт о человеке. М.: Гардарика, 1998. 784 с.

5. Гайденко П.П. Герменевтика и кризис буржуазной культурно-исторической традиции // Вопросы литературы. М., 1977. № 5. С. 130-165.

6. Губман Б.Л. Смысл истории. М.: Наука. 1991. 192 с.

7. Unет Г.Г. История как проблема логики. М.: Памятники исторической мысли, 2002. $1168 \mathrm{c}$.

Khamitov Ramil M. National Research Tomsk State University (Tomsk, Russian Federation).

E-mail: rams2601@yandex.ru;

DOI: $10.17223 / 1998863 X / 37 / 11$

INTERPRETATION IN THE CONTEXT OF DILTHEY'S HUMANITARIAN PROJECT

Key words: W. Dilthey, interpretation, history, hermeneutics, human sciences.

The art of understanding or hermeneutics has a rich history. For Aristotle hermeneutics is mostly a means of decoding grammatical structures. In the Middle Ages there began a tendency to interpret not only the Bible but secular literature. Hermeneutics gradually acquires the character of universality. In the case of Dilthey it becomes the foundation of the human sciences.

The emphasis on understanding in the humanities has its own history and its foundation. Initially, it gave priority to the psychological introspection. Whatever negative criticism it was exposed, it started the search for techniques that could provide the humanities with a firm foothold in the scientific world.

The inability to identify the verification procedures of empathy and the inability of ultimate coincidence between the researcher who reads the text and the historical hero gave Dilthey the idea to rely on the interpretation but not on psychological introspection. The individuals in relation to each other have a certain indissoluble communicative link. It emerges despite national and linguistic differences. The fact that people belong to one type creates a thread of understanding between them. Understanding can be presented within the framework of the interpretation and its various methods. 
The article discusses the hermeneutic method as a basis for Dilthey's historical researches. It is the final point of his quest and has much in common with mentioned above communicative link, thanks to which it is possible to satisfy the interest of knowing human history.

\section{References}

1. Dilthey, V. (2000) Sobranie sochineniy: $v 6 t$. [Collected Works. In 6 vols]. Vol. 1. Moscow: Dom intellektual'noy knigi.

2. Gadamer, G.G. (1988) Istina i metod [Truth and Method]. Translated from German. Moscow: Progress.

3. Dilthey, V. (2004) Sobranie sochineniy: v $6 t$. [Collected Works. In 6 vols]. Vol. 3. Moscow: Tri kvadrata.

4. Cassirer, E. (1998) Izbrannoe. Opyt o cheloveke [Selected Works. Experience about a person]. Translated from German. Moscow: Gardarika.

5. Gaydenko, P.P. (1977) Germenevtika i krizis burzhuaznoy kul'turno-istoricheskoy traditsii [Hermeneutics and the crisis of the bourgeois cultural and historical tradition]. Voprosy literatury. 5. pp. 130-165.

6. Gubman, B.L. (1991) Smysl istorii [The meaning of history]. Moscow: Nauka.

7. Shpet, G.G. (2002) Istoriya kak problema logiki [History as a problem of logic]. Moscow: Pamyatniki istoricheskoy mysli. 